\title{
STRUCTURAL VENEER BASED COMPOSITE PRODUCTS FROM HARDWOOD THINNING - PART I: BACKGROUND AND MANUFAC- TURING
}

\author{
Ian D. Underhill ${ }^{(1)}$, Benoit P. Gilbert ${ }^{(1)}$, Henri Bailleres $^{(2)}$, Robbie L. McGavin ${ }^{(2)}$, \\ Dale Patterson ${ }^{(3)}$ \\ (1) Griffith School of Engineering, Griffith University, Australia \\ (2) Salisbury Research Centre, Department of Agriculture, Fisheries and Forestry, Queens- \\ land Government, Australia \\ (3) Queensland Collage of Arts, Griffith University, Australia
}

\begin{abstract}
In Australia, plantation forests have increased in area by around 50\% in the last 10 years. While this expansion has seen a modest $8 \%$ increase for softwoods, hardwood plantations have dramatically increased by over $150 \%$. Hardwood plantations grown for high quality sawn timber are slow to mature, with a crop rotation time potentially reaching 35 years. With this long lead-time, each year the risk from fire, pests and adverse weather events dramatically increases, while not translating into substantially higher financial returns to the grower. To justify continued expansion of Australia's current hardwood plantation estate, it is becoming necessary to develop higher value end-uses for both pulpwood and smaller 'sawlog' resources. The use of the low commercial value stems currently culled during thinning appears to be a necessary option to improve the industry profitability and win new markets. This paper provides background information on Australian forests and plantations and gives an overview of potential uses of Australian hardwood plantation thinning logs, as their mechanical properties. More specifically, this paper reports on the development of structural Veneer Based Composite (VBC) products from hardwood plantation thinning logs, taking advantage of a recent technology developed to optimise the processing of this resource. The process used to manufacture a range of hollow-form veneer laminated structural products is presented and the mechanical characteristics of these products are investigated in the companion paper. The market applications and future opportunities for the proposed products are also discussed, as potential benefits to the timber industry.
\end{abstract}

\section{INTRODUCTION}

When establishing hardwood plantations for sawn timber, significant initial investment is essential to produce high quality logs at an early age (between 30 to 35 years) that have minimal knots and sufficient log diameter to produce high value sawn boards. Early pruning (i.e. removal of lower branches) and thinning (i.e. removal of low quality trees that are crooked, small or have too many branches), which increases the available light, moisture and nutrients to the remaining stand of trees, is essential during the early years of the plantation [1, 2]. 
For improved efficiency, a recommended stocking rate of around 1000 trees per hectare is usually adopted [3], and up to 700 trees can be removed before the plantation is clear felled in usually two main thinning operations. Nearly half of the trees are typically cut at 1.5 to 3 years in the first thinning, with another 300 being removed in the second thinning at 10 to 15 years.

Trees removed during the second thinning process usually have a Diameter at Breast Height Over Bark (DBHOB) of $150 \mathrm{~mm}$ to $300 \mathrm{~mm}$ and are generally deemed to have little commercial value. To justify continued expansion of Australia's current hardwood plantation estates, it is becoming necessary to develop high value end-use products for these small logs [2], as there are no clearly identified viable markets for these resources. Pulpwood is currently regarded as the only large scale viable option for these logs if the plantation is in close proximity (less than $100 \mathrm{~km}$ ) to a process facility and/or forms part of an overall harvest scheme [2].

This paper presents the initial joint research undertaken at Griffith University and the Salisbury Research Centre, Department of Agriculture, Fisheries and Forestry (DAFF), Queensland Government, to manufacture a range of high-value hollowform laminated Veneer Based Composite (VBC) products from hardwood plantation thinning. Specifically this paper provides an overview of Australian hardwood plantations, published various thinning applications and thinning mechanical properties. Laboratory based manufacturing process of the VBC products is introduced. This paper provides a review of potential market applications and future opportunities for the proposed VBC products. Planned future research is also discussed.

\section{BACKGROUND ON AUSTRALIAN FORESTS AND PLANTATIONS}

It is estimated that about $30 \%$ of Australia was covered by forests prior to the arrival of European settlers in the $18^{\text {th }}$ century. Today, about $40 \%$ of these forests have been lost, with the remaining native vegetation being highly fragmented [4]. Specifically, 149.4 million hectares of Australia is currently covered by forests, principally dominated by more than 700 different species of Eucalyptus. About two million hectares (1.34\%) of these forests are managed as plantations [5].

When establishing a plantation, a single species is usually chosen. To allow maximum yield in the shortest possible rotation time, industry requirements and environmental conditions are analysed and matched with an appropriate timber species [6]. In Australia, the yield from hardwood plantations can be up to $14 \%$ higher than from native forests [7] offering many financial and environmental advantages to the growers.

Overall, from 2000 to 2010 plantation forests in Australia have increased by about $51 \%$. This equates to a significant increase of $150 \%$ for hardwood plantations and an $8 \%$ increase for softwood plantations, as shown in Figure 1. This increase can be attributed predominantly to changes in government policies [8]. Today, a greater understanding exists between the need to balance the use of timber and the environmental and social importance of maintaining a diverse range of forests. 
Agreements that ban logging native forests have been signed around Australia [9], resulting in the promotion of alternative options, such as plantation timber.

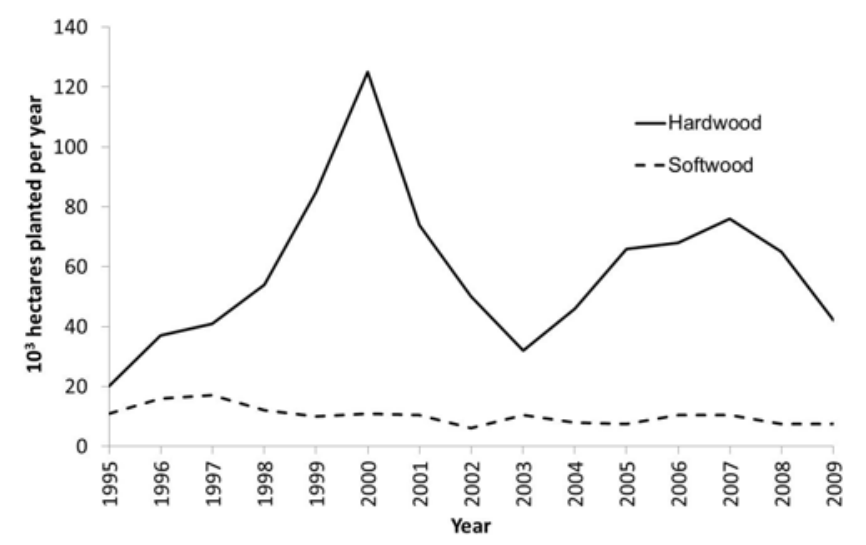

Figure 1: Plantation expansion between 1995 and 2009 [8]

Less than $10 \%$ of the hardwood plantations in Australia are grown for sawn timber. The remaining $90 \%$ are mainly grown for pulpwood and exported as unprocessed woodchips. Yet, partly due to the price of Australian woodchips being internationally uncompetitive, Australia has seen the recent collapse of major companies such as Willmott Forests, Great Southern Plantations and Timbercorp [10]. With this in mind, many growers have delayed or abandoned harvesting their pulpwood plantations until the market improves. These plantations are usually clear-felled at 10 to 12 years of age without prior thinning or pruning. In this type of plantation, species selection and breeding have focused on achieving high pulp yield, density and volume, which may adversely affect important mechanical properties for high value-added solid wood products $[11,12]$. These low-quality logs of similar size to thinning need also to be considered in creating higher endvalue products, such as the proposed VBC products in this study, and shift the focus of plantation management and harvesting practices. Moreover, as seen in Figure 1, more than 400,000 hectares of hardwood plantations have been planted around the year 2000 and a large quantity of thinning logs will be available in the coming years, reinforcing the need to develop a market for this type of resource, as well as pulpwood logs.

\section{LITERATURE REVIEW ON APPLICATIONS FOR PLANTATION THINNING}

\subsection{Round-wood form}

The most cost effective ways of utilising plantation thinning is to keep the logs in their natural round-form. Studies have highlighted potential applications for debarked logs, such as vineyard posts [13] or timber piles and posts for the building 
and landscaping industries [14-16]. These markets are well established in Australia, and are dominated by plantation softwoods, which are easy-to-work and readily available. Yet, hardwood plantation thinning logs have the advantage of being more durable and having higher mechanical properties, but for these logs to compete favourably, current problems with excessive splitting and checking, as depicted in Figure 2, need to be addressed [2].

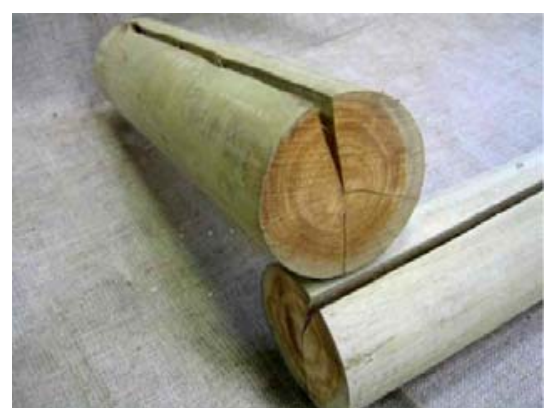

Figure 2: Split hardwood plantation thinning round wood logs (from [2])

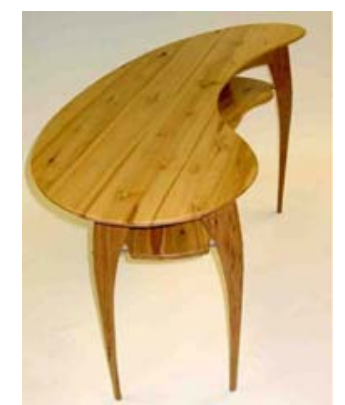

Figure 3: Furniture designed from hardwood plantation thinning timber (from [2])

\subsection{Solid wood products}

The use of hardwood plantation thinning for solid wood applications has also been successfully investigated in the fabrication of furniture by Training and Further Education (TAFE) students, as shown in Figure 3. For more industrial applications, trials were also conducted where sawn timber roof trusses and pallets were successfully manufactured [2]. High rates of rejection (more than 60\%) were reported in these studies due to defects in the material or subsequent material processing $[2,17]$.

\subsection{Structural products}

The Salisbury Research Centre investigated the use of thinning for structural applications from three hardwood species, namely Gympie messmate (Eucalyptus cloeziana), blackbutt (Eucalyptus pilularis) and red mahogany (Eucalyptus petti$t a$ ), and found that sawn thinning logs make attractive structural products if appropriately graded [2].

Material testing has also shown that, whilst having lower strength, hardness and density than the mature timber, the juvenile timber of these three species still has favourable properties when compared to radiata pine (Pinus radiata), a common softwood plantation timber grown in Australia. Additionally, the juvenile timber was found to have more favourable shrinkage and stability results than the mature tree [2]. Table 1 shows average reported material properties for juvenile and mature Gympie messmate and radiata Pine.

Other structural products investigated in [2] included plywood sheets and, more specific to the VBC products presented in this paper (see Section 4), Laminated 
Veneer Lumber (LVL) products. LVL products are manufactured by gluing veneer sheets together to form composite timber boards. Unlike plywood, the grains of all veneers are orientated in the same direction. The laminated manufacturing process randomises the location of the defects in the veneers and produces more uniform structural products, with higher strength and typically less variability in mechanical properties, than solid wood [18, 19]. These improved mechanical properties are especially important for thinning veneer based products, as thinning logs present a high proportion of natural defects (knots, resin veins etc.), as shown in Section 4.

Table 1: Average material properties (from $[2,19]$ )

\begin{tabular}{|c|c|c|c|}
\hline \multirow[b]{2}{*}{ Material Properties } & \multicolumn{2}{|c|}{ Gympie Messmate } & \multirow[b]{2}{*}{ Radiata Pine } \\
\hline & $\begin{array}{l}\text { Juvenile (less } \\
\text { than } 8 \text { year-old) }\end{array}$ & $\begin{array}{l}\text { Mature (between } \\
25 \text { to } 35 \text { year-old) }\end{array}$ & \\
\hline Basic Density & $648 \mathrm{~kg} / \mathrm{m}^{3}$ & $810 \mathrm{~kg} / \mathrm{m}^{3}$ & $400 \mathrm{~kg} / \mathrm{m}^{3}$ \\
\hline $\begin{array}{l}\text { Shrinkage Tangential } \\
\text { (green to } 12 \% \mathrm{MC} \text { ) }\end{array}$ & $4.6 \%$ & $5.9 \%$ & $4.5 \%$ \\
\hline $\begin{array}{l}\text { Shrinkage Radial } \\
\text { (green to 12\% MC) }\end{array}$ & $2.02 \%$ & $4.2 \%$ & $3 \%$ \\
\hline Janka Hardness Test & 6.8 & 12 & 3.3 \\
\hline $\begin{array}{l}\text { Modulus of Elasticity } \\
\text { (MOE) }\end{array}$ & $11.8 \mathrm{GPa}$ & $17 \mathrm{GPa}$ & $10 \mathrm{GPa}$ \\
\hline $\begin{array}{l}\text { Bending Modulus of } \\
\text { Rupture (MOR) }\end{array}$ & $106 \mathrm{MPa}$ & $137 \mathrm{MPa}$ & $81 \mathrm{Mpa}$ \\
\hline
\end{tabular}

The peeling of hardwood thinning logs using traditional peeling technology with driving dogs proves difficult [20] and generates poor yield, as the lathe is not well suited for low quality (i.e. large proportion of defects) and small diameter logs. On the other hand, spindle-less veneer lathe has proved well suited for processing small diameter logs, opening opportunities for the proposed thinning VBC products in Section 4. This type of lathe generally converts 80 to $90 \%$ of a log into green veneers, leaving an unpeeled core of about $45 \mathrm{~mm}$ diameter, as opposed to more than $130 \mathrm{~mm}$ diameter unpeeled cores in traditional peeling systems, as shown in Figure 4.

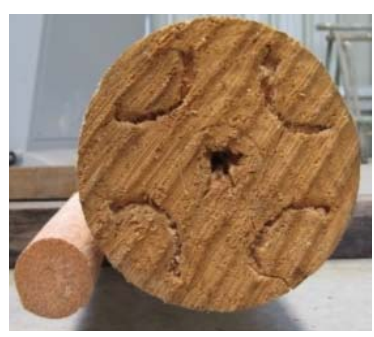

(a)

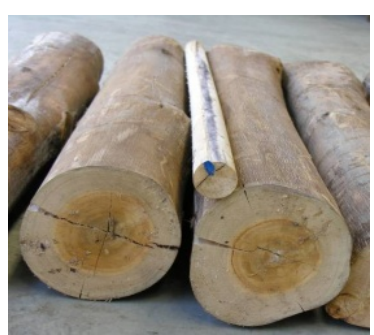

(b)

Figure 4: (a) Cores from spindle-less (left) and traditional (right) lathes, (b) thinning logs plus spindle-less core 


\section{CURRENT RESEARCH, DEVELOPMENT OF VENEER BASED COMPOSITE}

\subsection{General}

Samples of VBC products were manufactured at Griffith University using 15 year old plantation thinning Gympie messmate (Eucalyptus cloeziana). This species is currently one of the preferred hardwood plantation species for future development by the Department of Agriculture, Fisheries and Forestry, Queensland Government, in Queensland's sub-tropical areas [2]. Specifically in native forest, Gympie messmate is largely found in South-east Queensland. It predominantly occurs in tall open-forests and woodlands and is usually the dominant species in the stand. Under ideal growing conditions this species can attain $55 \mathrm{~m}$ in height with DBHOB of $2 \mathrm{~m}$. The heartwood is typically yellow-brown of even texture with a basic density of about $810 \mathrm{~kg} / \mathrm{m}^{3}$ and the highest durability class [19].

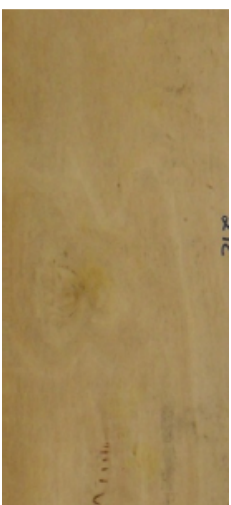

(a)

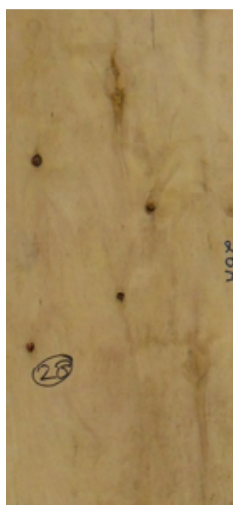

(b)

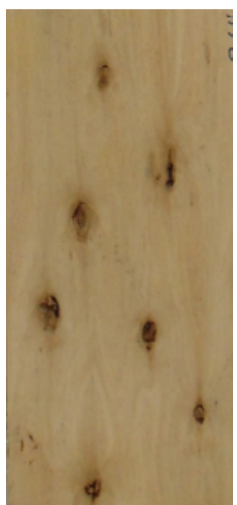

(c)

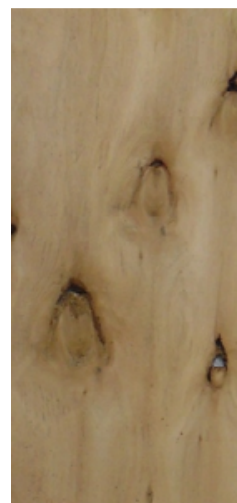

(d)

Figure 5: Examples of 15 year-old juvenile Gympie Messmate veneers used in this study from (a) low to (d) high proportion of defects

The logs used in this study had diameters of about $230 \mathrm{~mm}$ and were cut in $1.2 \mathrm{~m}$ lengths before being rotary peeled into nominal $1.7 \mathrm{~mm}$ thick veneers at the Salisbury Research Centre. Figure 5 shows some typical veneers ranging from veneers with low (Figure 5 (a)) to high (Figure 5 (d)) proportion of natural defects.

Samples of hollow-formed VBC products, namely circular hollow sections (CHS) (see Figure 6 (a)), rectangular hollow sections (RHS) (see Figure 6 (b)), Ceesections (see Figure 6 (c)) and I-sections (see Figure 6 (d)) were manufactured using the process described in Section 4.2. In addition to being manufactured from waste material, advantages of the new products over sawn timber sections lie with the products (i) having efficient cross-sectional shapes, (i.e. hollow, Cee or I shapes) and (ii) being able to be manufactured in large sizes currently not available in timber. Similar cross-sectional shapes have been successfully used in timber construction, mainly with glued composite box beams and I-beams. The latter products typically have a wood based panels for the web (i.e. plywood and parti- 
cleboard for instance), and structural timber for the flange (i.e. LVL or sawn timber for instance).

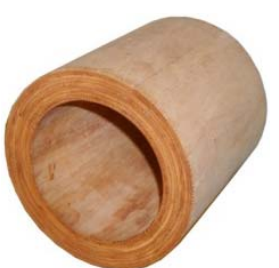

(a)

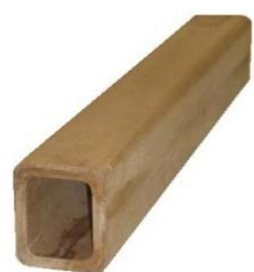

(b)

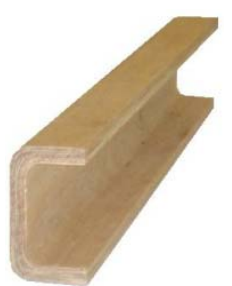

(c)

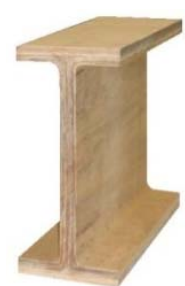

(d)

Figure 6: Sample of profiles manufactured at Griffith University (a) circular hollow section, (b) rectangular hollow section, (c) Cee-section, and (d) I-section

\subsection{Manufacturing process}

A self-reacting frame was designed and manufactured (see Figure 7 (a)) to construct the VBC sections. The manufacturing concept uses the natural tendency of the veneers to roll about one side, making their gluing into half-shapes achievable around a mandrel, with the veneer grain orientated in the same direction. Specifically, a pre-glued veneer stack is first sandwiched between Teflon sheets to minimise friction and allow the stack to shape around the mandrel. The stack is then positioned inside a series of flexible outer straps (see Figure 7) and a hydraulic jack drives the mandrel down, compressing the veneer stack between the mandrel and the outer straps. Rubber sheets are also inserted between the straps and the Teflon sheets to uniform the applied pressure and compensate non-uniform thickness of the veneers. By changing the shape of the inner mandrel, a variety of different VBC sections can manufactured, as shown in Figure 8 (a) for circular hollow sections and Figure 9 (a) for rectangular hollow sections, Cee-sections and Isections.

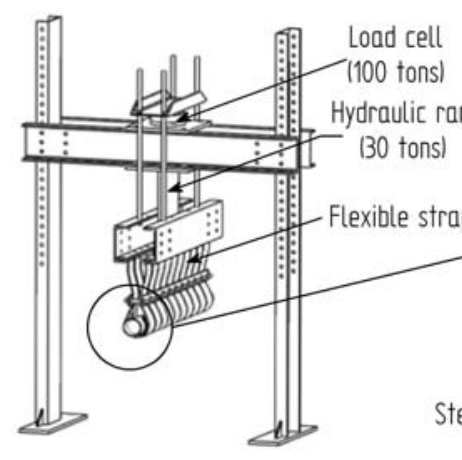

(a)

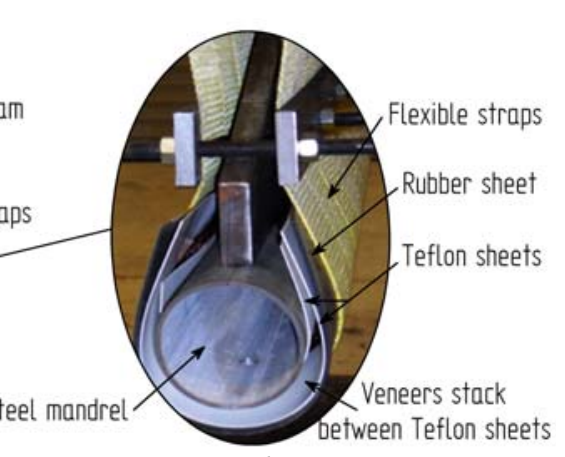

(b)

Figure 7: (a) 30T Self-reacting frame and (b) detailed view 
For circular hollow sections in Figure 8 (a), the applied pressure $P$ to the veneer stack is given in terms of the applied force $F$ as,

$$
P=\frac{F}{2 R L}
$$

where $R$ is the radius of the cross-section and $L$ the length of the profile. For rectangular cross-sectional shapes in Figure 9 (a), external pressure has to be applied to the flat sides of the profile. This process is currently being improved, using a vacuum press for instance.

To form complete cross-sections, two half-shapes are typically butt joined together glued back-to-back as shown in Figure 8 (b) and Figure 9 (b).

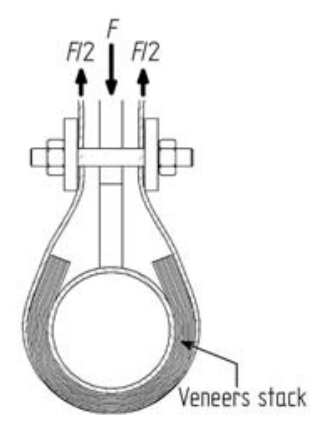

(a)

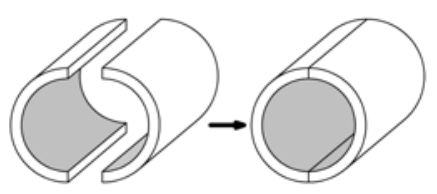

(b)

Figure 8: (a) Manufacturing of half-round shapes and (b) forming the circular hollow sections

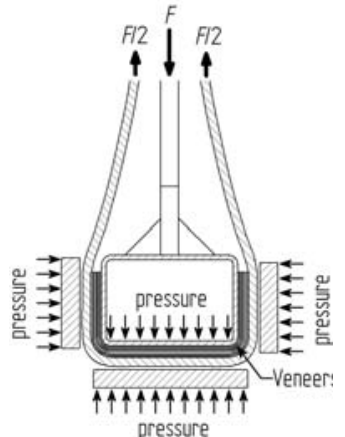

(a)

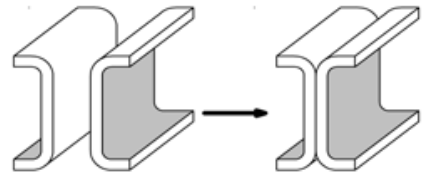

(b)

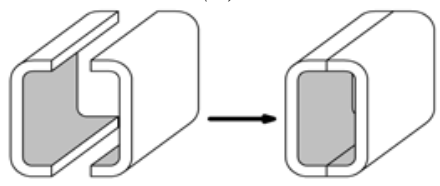

(c)

Figure 9: (a) Manufacturing of Cee-sections, (b) forming the I-sections and (b) forming the rectangular hollow sections

\subsection{Opportunities}

Various market opportunities have been identified for the proposed products.

- Circular hollow sections are currently being structurally investigated in the companion paper [21] as an alternative solution for Australia's supply shortage of high quality utility poles (also referred to as "power" poles). Hollow poles 
would be slid in a cylindrical concrete footing, or galvanised steel tube bolted to a concrete pad. Connecting the hollow poles above ground would considerably limit termite attacks and premature rotting conditions, thus allowing using less harmful wood treatment chemicals than currently practised in solid poles. Moreover, the proposed poles would offer lower transportation and installation costs when compared to solid timber, concrete and steel poles.

- Potential applications of rectangular hollow sections include the need highlighted by the energy industry for large sections of hardwood timber for crossarms of utility poles.

- Beyond the energy industry, since these components have high stiffness and strength per unit weight, it is believed that the hollow cross-sectional shapes have many potential applications in the building industry, either in large or small cross-sections. The proposed VBC products can be industrially produced in standard lengths and marketed in conjunction with a range of 'click-lock' fittings or more permanent connections, designed to rapidly join together lengths of sections in trusses, beams or columns for instance. Specifically, the 'clicklock' fittings would allow rapid assembly and disassembly of pre-designed structures, such as flat-packed house frames, roof trusses, emergency housing structures or DIY projects. Additionally, the hollow central void can be used to accommodate services, such as electrical, lighting, gas or water.

- I-sections manufactured from plantation thinning can be both used for structural and decorative applications in residential and the commercial buildings, where architecturally exposed elements are sought.

The use of these forms is currently being investigated with architecture students at Griffith University for both structural and architectural applications.

\section{FUTURE RESEARCHES AND CHALLENGES}

A constraint of the rotary peeling process is the short log lengths that spindle-less lathes can accommodate, $1.2 \mathrm{~m}$ at the Salisbury Research centre for instance. To manufacture usable lengths (typically $3 \mathrm{~m}$ for columns and $8 \mathrm{~m}$ for beams) of VBC products for engineering applications, subsections need to be jointed together or manufactured in a continuous process, similar to LVL products.

Due to their cross-section shape, the walls of the proposed VBC products in bending will mainly undergo compression, tension or shear, and various joint details were therefore preliminary investigated in tension in a $500 \mathrm{kN}$ MTS universal testing machine, at ambient temperature and humidity. LVL flat panels were manufactured from thinning veneers using a two parts phenol-resorcinol formaldehyde structural adhesive and six coupons (dog bone samples) were cut from each panel. Three coupons were used as control samples, while the remaining coupons were cut in half and joined back together. Lap, finger, butt and various scarf joints were investigated using either resorcinol adhesive or structural epoxy. Likely due to higher level of extractives present in juvenile Gympie messmate than in mature trees $[19,20]$, the strength of the joints were significantly less than the control samples, ranging from an average of $9.4 \%$ (butt joint with Phenol-resorcinol) to $42.6 \%$ ( $30^{\circ}$ scarf joint with epoxy) of the strength of the control samples. There- 
fore, joining lengths of VBC products together present a challenge. The Salisbury Research Centre is currently working on improving adhesives for use with juvenile hardwood thinning and steel-timber connections, consisting of inserting a steel sleeve in the hollow-form of similar stiffness and strength to the VBC product, are currently looked at.

Finally, for VBC products to be marketed, research is also required to develop design rules, enabling engineers and architects to safely use the proposed products, as further detailed in the companion paper [21].

\section{CONCLUSIONS}

This paper presented the development of Veneer Based Composite structural products manufactured from hardwood plantations thinning. Currently, hardwood plantations grown for sawn timber only achieve financial benefits on tree maturity (i.e. at 25 to 35 years) and create a challenging economic business model. Developing high-value products from thinning can generate revenue at plantation midcycle (i.e. between 10 to 15 year) and therefore significantly benefit the Australian plantation and timber industries. Specifically, if markets can be developed for the proposed products, growers in both the sawn timber and pulpwood markets may switch and clear fell their crops early, solely for the production of VBC products. This paper also introduced the manufacturing process of the proposed VBC products, potential applications and research opportunities currently being investigated.

\section{ACKNOWLEDGMENTS}

The authors would like to thank the Department of Agriculture, Fisheries and Forestry, Australian Government and Forest and Wood Products Australia for their financial support through the "2012 Science and innovation award for young people in agriculture, fisheries and forestry”, Forestry category.

\section{REFERENCES}

[1] R. Geoff, B. Smith, P. Brennan, First thinning in sub-tropical eucalypt plantations grown for high-value solid-wood products: a review, Northern Research Unit, Forests NSW Plantations Division, 2006.

[2] R.L. McGavin, M.P. Davies, J. Macgregor-Skinner, H. Bailleres, M. Armstrong, W.J. Atyeo, J. Norton, Utilisation Potential and Market Opportunities for Plantation Hardwood Thinnings from Queensland and Northern New South Wales, PN05.2022, Department of Primary Industries and Fisheries, Queensland Department, 2006.

[3] Qld DPI, Managing Hardwood Plantations, http://www2.dpi.qld.gov.au/hardwwodsqld/1815.html, Accessed on 22/03/2010.

[4] B.J.A. Corey "Little Left to Lose: Deforestation and Forest Degradation in Australia since European Colonization", Journal of Plant Ecology, 2011.

[5] Bureau of Rural Science, Australian Forest at a Glance, Department of Agriculture, Fisheries and Forestry, Australian Government, 2010. 
[6] B. Underhill, H. Watts, An overview of the commercial growing management and processing of forest products in Queensland, 2004.

[7] A.G. Department of Primary Industries and Fisheries, A.G. Department of Primary Industries and Fisheries, Plantations and Farm Forestry, http://www.daff.gov.au/forestry/australias-forests/plantation-farm-forestry,

Accessed on 24/05/2013.

[8] Bureau of Rural Science, Australian Plantation 2010 Inventory Update, Department of Agriculture, Fisheries and Forestry, Australian Government, 2010.

[9] Australian Government, Department of Agriculture Fisheries and Forestry, Regional Forest Agreements, http://www.daff.gov.au/forestry/policies/rfa, Accessed on 01/06/2013.

[10] A. White, Gunns growers challenge PPB in: The Australian, Australia, 2012.

[11] H. Bailleres, J. Gerard, M. Fournier, B. Thibaut "Wood quality of eucalyptus from plantations. 1. Spatio temporal variations and influence factors of three basic properties", IAWA journal, 16, 9-10, 1995.

[12] H. Bailleres, J. Gerard, M. Fournier, B. Thibaut "Wood quality of eucalyptus from plantations. 2. End splitting and sawing distorsion", IAWA journal, 16, 10, 1995.

[13] K.J. McCarthy, L.J. LCookson, M. Mollah, J. Norton, J. Hann, The Suitability of Plantation Thinnings as Vineyard Posts, Forest and Wood Products Research and Development Corporation, 2005.

[14] G. Nolan, R. Washusen, S. Jennings, B. Greaves, M. Parson, Eucalypt Plantations for Solid Wood Products in Australia. A Review, PN04.3002, Forest and Wood Products Research and Development Corporation, Australian Government, 2005.

[15] A. Ranta-Maunus, Round small-diameter timber for construction, Final report of project FAIR CT 95-0091, VTT Technical Research Centre of Finland, Finland, 1999.

[16] M. Dickson, G. Hopewell, C. MacKenzie, H. Bailleres, J. Switala, C. Thomas, A market assessment and evaluation of structural roundwood products from hardwood pulp plantations, Project PRA154-0910 Forest \& Wood Products Australia, Melbourne, Australia, 2011.

[17] R. Washusen, Processing plantation-grown Eucalyptus globulus and E. nitens for solid-wood products-is it viable?, Tech. Report 209, CRC for Forestry, 2011.

[18] J. Carrick, K. Mathieu, "Durability of Laminated Veneer Lumber made from Blackbutt", Proceedings of the 10DBMC International Conference On Durability of Building Materials and Components, France, 2005.

[19] K.R. Bottle, Wood in Australia, Types, properties and uses, (McGraw-Hill), Sydney, Australia, 1983.

[20] B. Ozarska "A review of the utilisation of hardwood for LVL (CSIRO)", Wood Science and Technology, 33, 1997.

[21] B.P. Gilbert, I.D. Underhill, H. Bailleres, R.L. McGavin, "Structural Veneer Based Composite products from hardwood thinning - Part II: Testing of hollow utility poles", Proceedings of the RILEM Conference "Materials and Joints in Timber Structures - Recent Advancement of Technology”, Stuttgart, Germany, 2013. 